\title{
THE FORMATION OF ANTI-CORROSIVE STRUCTURES AND THIN FILMS ON METAL SURFACES BY APPLYING EDM
}

\author{
Pavel Topala ${ }^{1 *}$, Alexandr Ojegov ${ }^{1}$, Vitalie Besliu${ }^{1}$, Petru Stoicev ${ }^{2}$ \\ ${ }^{1}$ Alecu Russo Balti State University, 38, Pushkin Str., MD-3100, Balti, Republic of Moldova \\ ${ }^{2}$ Technical University of Moldova, 168, Stefan cel Mare Bd., MD-2004, Chisinau, Republic of Moldova \\ ${ }^{*}$ Corresponding author: Pavel Topala, pavel.topala@gmail.com
}

Received: November, 10, 2018

Accepted: December, 12, 2018

\begin{abstract}
The methods of formation anti-corrosive strata and thin films on metal surfaces by applying electric discharge machining (EDM) are presented in this chapter. It has been demonstrated the increase of anti-corrosion resistance of metal surfaces by the formation of palladium depositions, carbon films and oxide and hydroxide films. Corrosion and electrochemical behavior of titanium with palladium powder coatings were investigated in sulfuric acid solutions at temperatures of 80 and $100^{\circ} \mathrm{C}$. In order to increase the diffusion of palladium in the base material and to increase the layer homogeneity, after coating, the samples were annealed in vacuum at $1150{ }^{\circ} \mathrm{C}$ for 1 hour. The proposed method allows to reduce the corrosion speed of titanium at least by 2 orders (from 18.7 down to $0.3 \mathrm{~g} \cdot \mathrm{m}^{-2} \cdot \mathrm{h}^{-}$ ${ }^{1}$ ), the corrosion potential is changed towards positive values (from $-0.56 \mathrm{mV}$ to $+0.3 \mathrm{~V}$ ). The research on surface electrical resistance and resistance to corrosion of oxide and hydroxide films formed on steel C45 surfaces by applying EDM have shown that the surface electrical resistance of the samples increased by $10^{7}$ times, the potential of corrosion increased from $-0.44 \mathrm{mV}$ to $+0.4 \mathrm{~V}$, the resistance to corrosion has increased by about 2 times in $1 \% \mathrm{NaCl}$ water solution, and by about 10 times in $30 \% \mathrm{H}_{2} \mathrm{SO}_{4}$ water solution. The less pronounced increase of anti-corrosion properties is possessed by carbon films formed on the same steel C45 surface, instead they increase superficial microhardness, the functional durability and processing productivity of the active piece surfaces.
\end{abstract}

Keywords: carbon, corrosion, electric discharge machining, microhardness, thin films.

\section{Introduction}

Corrosion is a damaging process for the absolute majority of parts that work in active environments, from the chemical point of view, and becomes even more pronounced when they operate in energy fields of different types: of high temperatures, of light, of electrical action, etc. It consists in the destruction of metallic materials under the chemical or electrochemical action of the environment or the substances they come into contact with.

With the exception of noble metals, all other metals are unstable in contact with the atmospheric air and aggressive environments. The way this instability manifests itself, and the degree to which it occurs, depends on the nature of the metal and the environment in which it is placed. 
Two types of corrosion can be highlighted considering the deployment mechanism: chemical corrosion [1] which refers to the processes of destruction of metals and alloys produced in dry gases, as well as, in liquids without electrical conductivity and in most organic substances, and electrochemical corrosion [1,4-10] which causes processes of metal and alloy degradation in electrolyte solutions in the presence of humidity, accompanied by the flow of electric current through the metal.

In all cases, when talking about the functionality of the machines and apparatuses or the parts from which they are assembled and their durability, the process of component degradation of different constructions is a damaging one. Throughout the practical encountered corrosion problems, it is important to know the real speed the process is taking place. If the corrosion process is possible, but has a very low deployment speed, the material is considered corrosion resistant.

Taking into account that iron and its alloys are used in the contemporary construction of machinery and apparatus as basic materials, and, on the other hand, a material for present and future is considered to be titanium and its alloys, in the following, we will focus on the research of behaviour of these materials in different working environments.

In the case of iron, its corrosion takes place in stages by its oxidation in the atmosphere with the formation of iron oxides (rust).

During the first stage of iron oxidation, $\mathrm{FeO}$ is formed, ferrous oxide, which is stable only in the absence of oxygen. When atmospheric oxygen appears, iron oxide is converted into iron hydroxide $\left(\mathrm{Fe}_{2} \mathrm{O}_{3} \cdot \mathrm{H}_{2} \mathrm{O}\right)$ or $\mathrm{FeO}(\mathrm{OH})$, as of which 2 phases are known:

- Phase 1 that corresponds to a large excess of oxygen;

- Phase 2 characterized by an insufficient amount of oxygen, which is why oxidation evolves slowly.

Depending on their colour, there are three types of rust:

1. $\mathrm{Fe}(\mathrm{OH})_{2}$ white rust, formed after the reaction:

$\mathrm{Fe}+2 \mathrm{H}_{2} \mathrm{O} \rightarrow \mathrm{Fe}(\mathrm{OH})_{2}+\mathrm{H}_{2}$

This type of rust quickly passes through oxidation to brown rust, which is why it is rarely seen.

2. Brown rust occurs as a result of the following reaction:

$4 \mathrm{Fe}(\mathrm{OH})_{2}+\mathrm{O}_{2} \rightarrow 4 \mathrm{FeO}(\mathrm{OH})+2 \mathrm{H}_{2} \mathrm{O}$

3. The black rust is made of ferrous and ferric oxide; being also called magnetite because of its magnetic properties and it is considered to be the most stable form of iron oxide. It forms a protective layer on the surface of the metal, with a homogeneous and adherent structure. The reaction is as follows:

$2 \mathrm{FeO}(\mathrm{OH})+\mathrm{Fe}(\mathrm{OH})_{2} \rightarrow \mathrm{Fe}_{3} \mathrm{O}_{4}+2 \mathrm{H}_{2} \mathrm{O}$.

Iron and its alloys are reacted with electrochemically active acids and salts of metals with the destruction of the workpiece surface in working environments:

$\mathrm{Fe}+\mathrm{H}_{2} \mathrm{SO}_{4} \rightarrow \mathrm{FeSO}_{4}+\mathrm{H}_{2}$

$\mathrm{Fe}+2 \mathrm{HCl} \rightarrow \mathrm{FeCl}_{2}+\mathrm{H}_{2}$

$\mathrm{Fe}+\mathrm{CuSO}_{4} \rightarrow \mathrm{FeSO}_{4}+\mathrm{Cu}$

$\mathrm{Fe}+2 \mathrm{NaCl} \rightarrow \mathrm{FeCl}_{2}+2 \mathrm{Na}$.

Titanium and its alloys are more resistant to corrosion, since, under normal conditions in the atmosphere, the $\mathrm{TiO}_{2}$ oxide film is formed, which is stable in different environments, other than those alkaline, for instance:

$\mathrm{TiO}_{2}+\mathrm{Na}_{2} \mathrm{CO}_{3}\left(\mathrm{~K}_{2} \mathrm{CO}_{3}\right) \rightarrow \mathrm{Na}_{2} \mathrm{TiO}_{3}\left(\mathrm{~K}_{2} \mathrm{TiO}_{3}\right)+\mathrm{CO}_{2}$ 
Under certain conditions (high temperature, high concentration), titanium also reacts with some acids:

$$
\begin{aligned}
& \mathrm{Ti}+\mathrm{H}_{2} \mathrm{SO}_{4} \rightarrow \mathrm{TiSO}_{4}+\mathrm{H}_{2} \\
& 2 \mathrm{Ti}+3 \mathrm{H}_{2} \mathrm{SO}_{4} \rightarrow \mathrm{Ti}_{2}\left(\mathrm{SO}_{4}\right)_{3}+3 \mathrm{H}_{2} \\
& \mathrm{Ti}+8 \mathrm{HNO}_{3} \rightarrow \mathrm{Ti}\left(\mathrm{NO}_{3}\right)_{4}+4 \mathrm{NO}_{2}+4 \mathrm{H}_{2} \mathrm{O} \\
& 2 \mathrm{Ti}+6 \mathrm{HCl} \rightarrow 2 \mathrm{TiCl}_{3}+3 \mathrm{H}_{2} \\
& 2 \mathrm{Ti}+6 \mathrm{HBr} \rightarrow 2 \mathrm{TiBr}_{3}+3 \mathrm{H}_{2} \\
& 2 \mathrm{Ti}+6 \mathrm{HI} \rightarrow 2 \mathrm{Til}_{3}+3 \mathrm{H}_{2} \text {, etc. }
\end{aligned}
$$

They destroy the base metal and cause further damage of the workpieces in those environments.

The methods and techniques of anticorrosive protection are various and numerous and they can be grouped into the following categories [2]:

- methods of preventing corrosion;

- use of metals and alloys resistant to corrosion;

- methods of influencing the corrosive medium [33, 34];

- methods of covering metal surfaces with protective layers [11, 19, 32];

- passivation of surfaces by depositing anticorrosive strata, etc.

The essence of preventing corrosion consists in [2]:

- choosing the correct option of materials used in building devices, industrial equipment from the point of view of resistance to corrosion;

- avoiding the contact of two metals, one of which is more electronegative than the other, e.g. aluminium and copper alloys or alloyed steel, bronze and steel, etc;

- avoiding the contact of cold-hardened metals with annealed or cast metals, for the reason that due to the difference of electrochemical potential between them, the last one corrodes in the presence of an electrolyte;

- choosing a more careful processing of the metal surface, since hollows and scratches favour and accelerate corrosion.

The group of metals and alloys resistant to corrosion contain noble metals in their alloys, but their use becomes difficult because of the high cost. Self-protective metals and alloys will be used instead. These are metals and alloys which, after an initial corrosion, are covered with an isolating pellicle or film as a result of the passivation phenomenon (e.g. the passivation of $\mathrm{Ag}$ in $\mathrm{HCl}$ by forming the $\mathrm{AgCl}$ film of $\mathrm{Fe}$ in $\mathrm{HNO}_{3}$ concentrated through the formation of the $\mathrm{Fe}\left(\mathrm{NO}_{3}\right)_{3}$ pellicle, etc).

In most cases, metals are alloyed with an adequate component. Sometimes the relatively low concentration of the alloyed component considerably reduces the corrosion speed (e.g. the introduction of such elements as $\mathrm{Cu}, \mathrm{Cr}$ or $\mathrm{Ni}$ of $0.2 \ldots 0.3 \%$ in steels, etc).

There are many cases when it is possible to influence the corrosive medium to lower the speed of corrosion. There are many possibilities.

The following can be mentioned [2]:

- modification of the $\mathrm{pH}$, which means bringing it to a convenient value for the metal that is to be protected. This consists in the elimination from the medium of corrosion, by use of physical, chemical and mechanic methods (e.g. neutralization of waste water with chemical substances);

- removal of gases $\left(\mathrm{O}_{2}\right.$ and $\left.\mathrm{CO}_{2}\right)$, which increase the speed of corrosion in corrosive media, particularly that of the water; 
- use of inhibitory elements (organic or inorganic substances) [33, 34], which, being introduced in small quantities in the corrosive medium, lower or completely annihilate its corrosive capacity;

- cathode protection (electro-defence) means the use of galvanic methods of metal protection with the help of auxiliary metal anodes, which take over the corrosive capacity of the medium, thus protecting the material used for the workpiece.

The protection realized by applying anticorrosive layers $[2,11,19,32]$ means to cover the metal with a thin layer or self-protective material. The self-protective layer should meet the following requirements: it should be compact and adherent, it should be elastic and plastic enough, and its thickness should be uniform in addition to being as small as possible. The protective layer may be metallic or non-metallic. Metallic deposits may be realized through different methods: galvanic, thermal, through plating, laser radiation, bombarding with ions, alloying by means of electric discharge machining, etc. The formed surface layers, except those obtained through plating, usually present a certain porosity, which determines the appearance of local portions of corrosion with all the consequences. Non-metallic protective layers may be organic or inorganic, realized with the help of varnish, paints, enamels or plastic thin sheets.

The formation of inorganic thin films or pellicles (oxide or graphite) on the workpiece surface is a progressive method of anticorrosive protection of superficial layers. The oxide or the graphite, being much more passive than the proper metal, and, in the interaction with the work media lowers the corrosive potential of the whole piece. The key problem that should be solved is the one that deals with the formation of structurally stable deposits with a high mechanic and electric resistance, having a uniform continuity and thickness on the whole surface.

The choice of the method to be used for the production of the protective layer depends on [2]:

- the conditions and working surroundings of the piece;

- the shape and the dimensions of the protective item;

- the quality of the supportive material or of the protected item;

- the functional technological parameters of the device;

- the way the item to be protected is placed in the device;

- the technologies of application and executive possibilities for anticorrosive protection.

\section{Methodology of experimental investigations \\ Experimental setup}

The experimental setup for the formation of anticorrosive coatings on the metal surfaces of the parts by applying pulsed electric discharge machining (PEDM) comprises the following electric blocks: the power pulse generator, the priming block (intended for initiating the electrical discharge) and the control block, the role of which is to synchronize the power and the priming discharge pulses.

As a result of the specialty bibliographic analysis [11-19], it was concluded that, for the formation of these layers, RC-type generators, with parallel priming, can be successfully used. The deposition of layers of metallic powders with the use of electric fields is produced as a result of interaction of the powder particles with the plasma jet and the transport of the liquid and vapour phase on the surface of the piece-cathode [11,19]. The powder particles, 
having the dimensions of $(20 . .200) \mu \mathrm{m}$, are inserted in the $(0.3 . .1 .5) \mathrm{mm}$ gap at a capacitor voltage of $U_{c}=(80 \ldots 400) \mathrm{V}$.

\section{Methodology of anticorrosive coatings formation}

Research on the interactions of the plasma channel of PEDM with the surfaces of the electrodes have shown that for the phenomenon of electroerosion two types of effects are characteristic: type I - the appearance of the "cold" electrode spots on the electrode surfaces, which give rise to the asperities and impurities on their surface $[11,19]$ and cause both, the cleaning of the surfaces of impurities and their thermal interaction, producing structural changes in the superficial layers of small thicknesses (just about the size of micro- and Nanometers); type II - on the electrode surfaces, after the "cold" electrode spots, the "warm" ones cause the essential melting of the electrode, accompanied by the vaporization phenomena and the dropping of the electrode material [19]. If type II interaction of the plasma channel with electrodes surfaces has found a rather wide application in dimensional processing [2227] and the deposition layer formation (both of the compact materials [18] and the powders $[11,19])$, then type I actions are described in the literature only as scientific findings, and for this reason, it is necessary to elucidate the conditions and the effects of surface thermal treatment and to reveal whether this type of interaction is purely thermal or is a thermochemical one.

Analyzing the results obtained by the author of the paper [19], it was established that, in order to obtain a type I interaction with the plasma channel (in the absence of surface melting) or type II interaction (when the liquid phase is attested) on the surfaces of the workpieces, it is necessary that the energy density emitted on the processed surface to be lower or higher than the specific heat of melting of the material, and the later can be appreciated by the relation [3, 13, 19]:

$$
\begin{gathered}
\frac{4 W}{\pi d_{c}^{2} \cdot S}<Q<\frac{4 W}{\pi d_{c}^{2} \cdot S}, \\
Q=q \rho
\end{gathered}
$$

where $q$ and $\rho$ are the specific heat of melting and the density of the workpiece material respectively; $W$ is the energy emitted in the gap, $d_{c}$ is the diameter of the plasma channel and $S$ is the gap value.

As it can be seen from the relation (1), at the time of the energetic processing regime, the size of the gap and the thermo-physical properties of the workpiece material are known, the diameter of the plasma channel can be determined, which coincides with the size of its trace on the processed surface. If a coefficient of overlapping of the traces (of type I or type II) $k=0,5 \ldots 1,0$ and the frequency of the electrical impulses f are known, the productivity of the technological process can be determined by the relation:

$$
\eta=\frac{k \pi d_{c}^{2} f}{4}
$$

In the paper [19], it has been demonstrated that when PEDM is applied for superficial processing, the erosion processes take place, accompanied by explosive melting and vaporization of the electrode material for the vast majority of studied metals and alloys, for 
the current pulse duration contained in the limits $10^{-4} \ldots 10^{-9} \mathrm{~s}$. It results that, in order to obtain the expected effects, it is necessary to provide a relatively low duration pulses of discharge.

Effects on electrode surfaces are a function depending on the way of the workpiece connection in the discharge circuit (as anode or as cathode) $[13,18,19]$. These desiderata have been studied in [19] and it has been established that for short-term discharge pulses they are "cathodic" and for the long-term ones they are "anodic", thus, in the case of superficial thermal treatments and deposition of materials, the workpiece will be included in the discharge circuit as cathode. In the case of thermal treatment of steel surfaces, their hardness increases by $2 . . .3$ times, and for titanium surfaces by 2 ...5 times, for the formed layers thicknesses from a few micrometres to several dozens of micrometres. The depth of these layers reaches a maximum at three passes of technological cycle for steels and at five passes for titanium and its alloys.

The interaction of the plasma channel with the surface of the electrode-workpiece is not always purely thermal, nonetheless the surface of the piece is often enriched with elements contained in the environment and with the contents of the tool-anode material. The penetration depth [19] of these elements in the superficial layer of the piece is a function of both the energy of the discharge pulse and the size of the gap, and can be expressed with the relation:

$$
h=\frac{k W_{S}}{A S}
$$

where $W_{S}=\int_{o}^{\tau} U(t) I(t) d t$ is the energy emitted in the gap during a singular discharge; $U$ and I is the voltage and the current in the gap, respectively; $\tau$ is the pulse duration; $A$ is the area of the workpiece surface processed at a singular discharge; $k$ is a constant that depends on the thermo-physical properties of the workpiece material.

\section{Technology of powder deposition formation}

From the results of the experimental researches carried out by the authors $[11,19]$ it has been demonstrated that, in order to obtain the powder depositions, it is necessary to introduce the powder in the anode zone of the gap. From a technological point of view, a parameter that needs to be predicted is the thickness of the deposition layer. This parameter is quite important, because in some cases it is determinant in the technological application of the method. Analyzing the experimental results of the authors of this chapter and those of the works $[15,16,19-21]$, in the case of the deposition layers of different materials, the following relationship was deduced for the deposition thickness:

$$
H=\frac{P^{c} \cdot f^{d} \cdot W^{k}\left(a-b S^{2}\right) \cdot r^{m}}{\rho \cdot A} \cdot n
$$

where $P$ is the powder flow; $f$ is the frequency of impulse discharges; $r$ is the equivalent radius of powder particles; $W$ is the energy released in the gap; $S$ is the size of the gap; $\rho$ is the density of the particles' material; $A$ is the area of the processed surface; $n$ is the number of passes of the tool-electrode on the workpiece surface; $a, b$ are individual constants of the deposition materials; $c, d, k, m$ are the power exponents that are experimentally established 
and constitute the both functions, of the properties of the powder material and of the processing conditions.

Taking into account the experimental results obtained by the authors of the papers $[18,19]$ for the determination of the thickness of the deposition layer, the relation (2.4) can be written as:

$$
H=\frac{\Delta m}{\rho \cdot A} \cdot n
$$

Where

$$
\Delta m=P^{c} \cdot f^{d} \cdot W^{k}\left(a-b S^{2}\right) r^{m}
$$

The uniformity of deposition of the layer is characterized by the thickness of the deposited layer (or by the dimension $\Delta \mathrm{m}$ on each surface unit). If the processing time is different during the manual processing on different surface portions, the surface is not continuous; the mechanization of the process ensures the formation of uniform deposition on the entire surface of the workpiece.

The compactness of the layers and the existence of recesses or asperities are visually appreciated or measured using the microscope analysis method.

\section{Technology of oxide films formation}

In order to achieve the experimental researches, the pulse current generator with priming from a high voltage block with $12 \mathrm{kV}$ voltage and $0.3 \mu \mathrm{A}$ current was used, the laboratory installation which ensures the positioning, fixing and rotation of the samples during the processing with an adjustable rotation frequency ranging from 0 to $150 \mathrm{rpm}$ [3]. The used tool-electrode was made in the form of cylindrical bar, rounded at the working end in the shape of a hemisphere and made of stainless steel. The cathode piece was a cylindrical bar $13 \mathrm{~mm}$ in diameter. The piece was firmly fixed to the tool-machine frame and the toolelectrode into the tool-port. The workpiece was connected to the pulse generator as cathode, and the tool-electrode as anode, their axes forming an angle of $90^{\circ}$. In the case of flat surface processing, both, the piece and the tool-electrode were made in the form of cylinders with a diameter of $10 \mathrm{~mm}$, they were firmly fixed to the tool-machine port with parallel active surfaces and the electric discharge scanning the workpiece surface by migration of the plasma channel on these surfaces at a processing cycle. As the material for the pairs of electrodes (workpiece/tool-electrode) were chosen: aluminum alloy AlCu4Mg1; steel C45; titanium alloy TiAl6Mo4, and copper alloys.

\section{Technology of graphite deposition formation}

Experimental research on graphite deposits was carried out under normal conditions in the air environment, under sub-excitation regime of PEDM. For the purpose of realizing the experiments, the power supply having the following parameters was used: the energy released in the gap $W_{S}=0 \div 4.8 \mathrm{~J}$, the energy accumulated on the capacitor battery $W_{c}=0 \div 12 \mathrm{~J}$, the voltage on the capacitor battery $U_{c}=0 \div 200 \mathrm{~V}$, the capacity $C=100 \div 600 \mu \mathrm{F}$ with step of 100 $\mu \mathrm{F}$, the gap value $\mathrm{S}=0.05 \div 2.5 \mathrm{~mm}$; discharge frequency $\mathrm{f}=0 \div 50 \mathrm{~Hz}$, impulse duration $\mathrm{T}=0 \div 250$ $\mu \mathrm{s}$. Due to these parameters, we can provide the PEDM operation under the regime of "hot" electrode spots (with the melting of the processed surfaces) and under the regime of the "cold" electrode spots (without melting the surfaces undergoing processing, although at Nano-meter scale it occurs). 
Between the two electrodes - a graphite cathode and an anode made of the metal specimen, micro-electric discharge is applied. The micro-electric arc that is produced for a very short period of time - microseconds - has a very high temperature of about $10^{4}{ }^{\circ} \mathrm{C}$. At this temperature the graphite erodes (in the form of separated carbon atoms or chemical compounds of the type $\mathrm{CO}$ and $\mathrm{CO}_{2}$ which further decompose into carbon and oxygen, the first being ionized, is deposited in the form of film on the metal surface and the oxygen is released in the plasma [3]) and due to the fact that it is in an electric field, the graphite particles in the vapour state are transported to the opposite sign electrode (anode) made up of the metal specimen. Thus, on the metal surface of the anode, a graphite layer of the micrometer dimension is deposited.

\section{Methodology for determining the corrosion potential and speed of the samples}

In order to measure the potential and the speed of corrosion, a set-up was developed, the scheme of which is shown in Figure 1. In a vessel 1 with electrolyte $2(3 \% \mathrm{NaCl}$ water solution for samples made of construction steels and $40 \% \mathrm{H}_{2} \mathrm{SO}_{4}$ water solution for titanium, copper and aluminium alloys samples), the sample and the cathode 6 are fixed. Cathode joins at the "-" pole, and the sample at the "+" pole of the DC source with smooth voltage regulation. A milliammeter is connected in serial with the source and a voltmeter, in parallel respectively. To measure the corrosion potential of the superficial oxide layer 4 , the base metal 3 is placed in a rubber gasket 5 having a hole 7 so that only the oxidized surface of the sample is in contact with the electrolyte. The voltage is gradually increasing until the current appears which will be indicated by the voltmeter - the value of the corrosion potential, and the milliammeter - the corrosion current. In order to increase the measurement precision, several measurements are made for different parts of the sample surface. In order to perform the chemical corrosion resistance tests of the processed samples (with PEDM-coated oxide films on the active surface), electrolytes from distilled water and chemical agents with the respective concentration at room temperature were prepared or, in separate cases, the device was continuously fed with an electrolyte of a certain temperature via a thermostat.
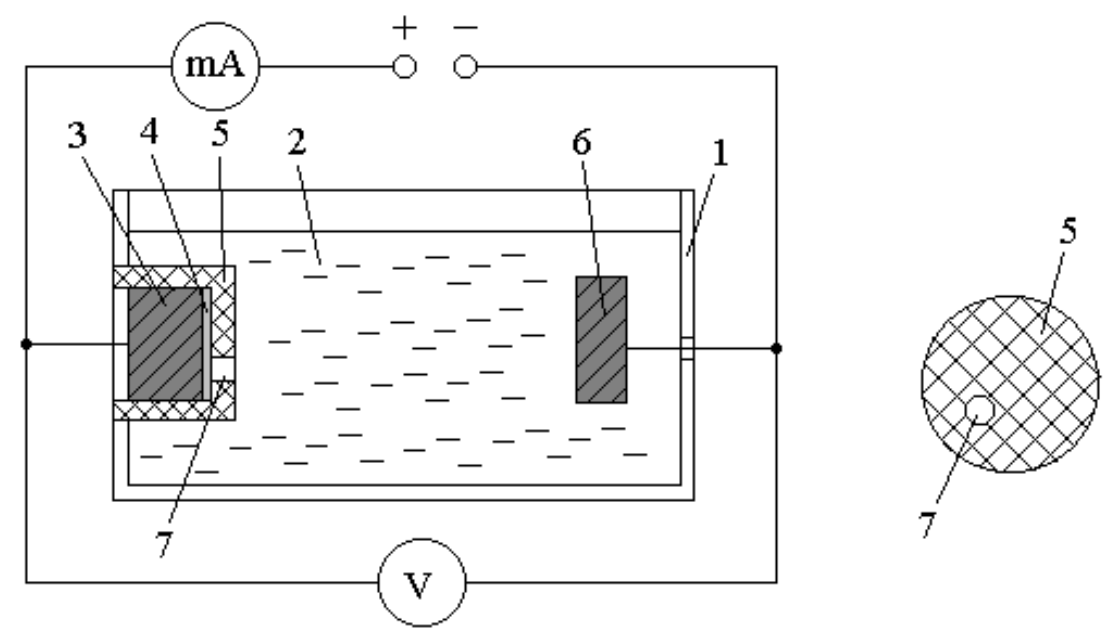

Figure 1. Potential and speed of corrosion measurement scheme: 1 - vessel;

2 - electrolyte; 3 - sample connected as anode; 4 -oxide layer; 5 - rubber gasket;

6 - cathode; 7 - hole for contacting the oxidized surface with the electrolyte in the water solution. 
The samples were firmly fixed in the prepared device (Fig. 2) so that only a circleshaped part of the processed surface was subjected to dissolution. This was included in the anode dissolution circuit as anode. The tests were carried out in the operating mode of the experimental DC installation and the $0.1 \mathrm{~V}$ step-by-step voltage change [3].

The corrosion speed is determined by weighing the samples before and after the test at the analytical electronic balance KERN ABS-N ABJ-NM with the accuracy of $10^{-5} \mathrm{~g}$.

The corrosion speed index is determined with the relation [3]:

$$
K=\frac{\Delta m}{S \cdot t}
$$

where $\mathrm{K}$ is the speed of corrosion (mass indicator), $\mathrm{g} \cdot \mathrm{m}^{-2} \cdot \mathrm{h}^{-1} ; \mathrm{S}$ is the area of the workpiece surface, $\mathrm{m}^{2}$; $\mathrm{t}$ is the test duration (work time), $\mathrm{h} ; \Delta \mathrm{m}$ is the mass lost (or the mass addition), $\mathrm{g}$ :

$$
\Delta \mathrm{m}=\mathrm{m}_{\mathrm{i}}-\mathrm{m}_{\mathrm{f}}
$$

where $m_{i}$ is the initial mass of the sample, $g ; m_{f}$ is the final mass of the sample, $g$.

\section{Results}

Determination of corrosion resistance of titanium and its alloys with deposited layers of metallic powder

In the process of deposition with electrodes made of compact materials by PEDM method, it is difficult to form layers with a full continuity, constant thickness, without pores, without impurities, etc., important elements for obtaining corrosion-resistant layers. The depositions obtained by the authors of the papers [13,19-21] have shown good results in their corrosion resistance. When depositing metal powders, it is possible to form layers with highest thickness, but the problem of porosity remains unresolved.

Up to now, detailed research has been carried out on the corrosion resistance of titanium samples on which palladium $(\mathrm{Pd})$, ruthenium $(\mathrm{Ru})$ and nickel $(\mathrm{Ni})$ depositions have been formed [20, 21]. The modification of the superficial titanium chemical composition with these metals was performed in order to obtain anodes on the base of titanium resistant to corrosion. The obtained results $[20,21]$ indicate that deposits formed by this method increase the corrosion resistance of titanium by about 5 times.

The corrosion and the electrochemical behaviour of titanium, with layers formed with the use of metal powders, were investigated by the authors [21] for the application of the $10 \% \mathrm{H}_{2} \mathrm{SO}_{4}$ solution in distilled water at temperatures of 80 and $100{ }^{\circ} \mathrm{C}$ respectively. After the formation of the layers, some of the samples were subjected to annealing in vacuum at 1150 ${ }^{\circ} \mathrm{C}$ for 1 hour for the purpose of palladium diffusion in the sample material. The corrosion and the electrochemical tests for the annealed samples were carried out in $10 \% \mathrm{H}_{2} \mathrm{SO}_{4}$ solution in distilled water at 80 and $100{ }^{\circ} \mathrm{C}$ and in $20,30,40 \% \mathrm{H}_{2} \mathrm{SO}_{4}$ solution in distilled water at 100 ${ }^{\circ} \mathrm{C}$. The palladium content was determined in the solution by the photo-calorimetric method. In the annealed samples, the palladium content was $5.6 \mathrm{mg} \cdot \mathrm{cm}^{-2}$.

The corrosion speed of titanium with powder depositions in $10 \% \mathrm{H}_{2} \mathrm{SO}_{4}$ solution in distilled water at $80{ }^{\circ} \mathrm{C}$ was $\left.0.2 \mathrm{~g} \cdot \mathrm{m}^{-2} \cdot \mathrm{h}^{-1}\right)$, and at $100{ }^{\circ} \mathrm{C}$ the first 5 hours of testing was 0.78 $\mathrm{g} \cdot \mathrm{m}^{-2} \cdot \mathrm{h}^{-1}$, and then, during the tests, the speed decreased and, in 50 hours of testing, has dropped to $0.3 \mathrm{~g} \cdot \mathrm{m}^{-2} \cdot \mathrm{h}^{-1}$. This situation of diminishing the corrosion speed can be caused by the dissolution of the unstable phases in the first hours. The corrosion potential, under these conditions, is situated within the passivity limits and equals to $+400 \mathrm{mV}$ in $10 \% \mathrm{H}_{2} \mathrm{SO}_{4}$ 
solutions at $80{ }^{\circ} \mathrm{C}$ (relative to the standard hydrogen electrode) and at $100{ }^{\circ} \mathrm{C}$ - equals to $+300 \mathrm{mV}$ compared to the titanium samples, without protecting depositions in the $10 \% \mathrm{H}_{2} \mathrm{SO}_{4}$ solution in distilled water, which actively dissolves at potential of $-0.56 \mathrm{mV}$ with the speed of $18.72 \mathrm{~g} \cdot \mathrm{m}^{-2} \cdot \mathrm{h}^{-1}$. Thus, we can state that, in the case of deposits application, the corrosion speed decreases up to 100 times.

After annealing, the corrosion speed has become even smaller.

For $10 \% \mathrm{H}_{2} \mathrm{SO}_{4}$ solution in water at $80{ }^{\circ} \mathrm{C}$, this was $0.056 \mathrm{~g} \cdot \mathrm{m}^{-2} \cdot \mathrm{h}^{-1}$ and at $100{ }^{\circ} \mathrm{C}$ the corrosion process was completely absent.

With increasing the solution concentration to 20,30 and $40 \% \mathrm{H}_{2} \mathrm{SO}_{4}$, respectively, in water, the corrosion rate at $100{ }^{\circ} \mathrm{C}$ increased accordingly to: $0.5,0.9$ and $1.8 \mathrm{~g} \cdot \mathrm{m}^{-2} \cdot \mathrm{h}^{-1}$. The corrosion potentials, under these conditions, is situated within the passivity limits and is equal to $10 \% \mathrm{H}_{2} \mathrm{SO}_{4}$ solution in water at $80{ }^{\circ} \mathrm{C}$ and $100{ }^{\circ} \mathrm{C}$ after 5 hours of testing to $+700 \mathrm{mV}$, in addition, corresponding to solutions containing 20,30 and $40 \% \mathrm{H}_{2} \mathrm{SO}_{4}$ in water, it ranged from +335 to $+400 \mathrm{mV}$ (Figure 2). For comparison, it can be mentioned that the corrosion speed of Pd layers in $10 \% \mathrm{H}_{2} \mathrm{SO}_{4}$ solution in water at $100{ }^{\circ} \mathrm{C}$, depending on the specific processing time and regime, varies from 0.1 to $0.8 \mathrm{~g} \cdot \mathrm{m}^{-2} \cdot \mathrm{h}^{-1}$. With increasing acid concentration in water, the speed increases for $40 \% \mathrm{H}_{2} \mathrm{SO}_{4}$ solution at $100{ }^{\circ} \mathrm{C}$ for different samples, ranging from 0.85 to $2.5 \mathrm{~g} \cdot \mathrm{m}^{-2} \cdot \mathrm{h}^{-1}$.

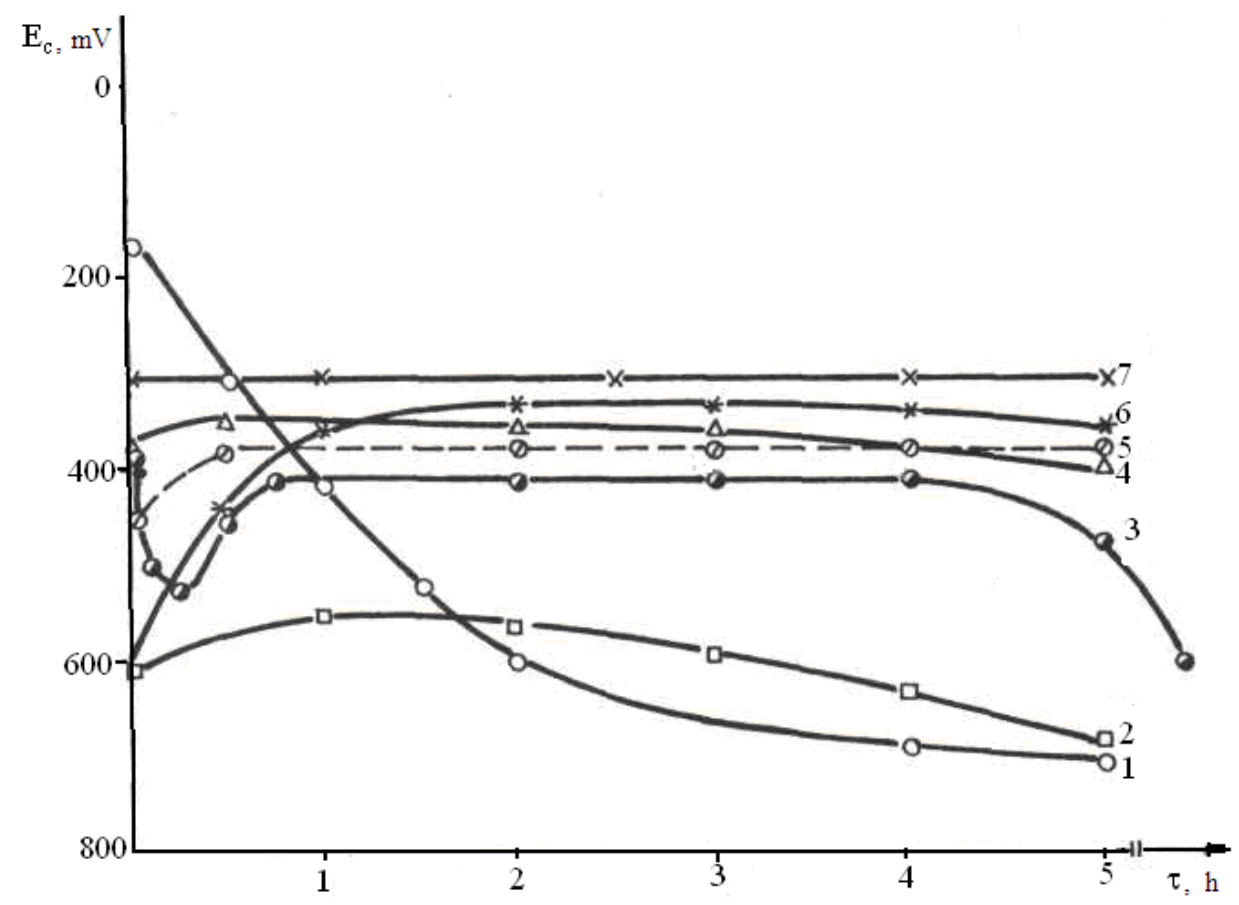

Figure 2. Changing in time the corrosion potential of palladium deposited samples (without annealing and after annealing) in water solutions of $10 ; 20 ; 30$ and $40 \% \mathrm{H}_{2} \mathrm{SO}_{4}$ at $80{ }^{\circ} \mathrm{C}$ and at $100{ }^{\circ} \mathrm{C}: 1-10 \% \mathrm{H}_{2} \mathrm{SO}_{4}, 80{ }^{\circ} \mathrm{C}$ without annealing; $2-10 \% \mathrm{H}_{2} \mathrm{SO}_{4}, 100{ }^{\circ} \mathrm{C}$, with annealing, $3-10 \% \mathrm{H}_{2} \mathrm{SO}_{4}, 80{ }^{\circ} \mathrm{C}$, without annealing; $4-40 \% \mathrm{H}_{2} \mathrm{SO}_{4}, 100{ }^{\circ} \mathrm{C}$, with annealing;

$5-30 \% \mathrm{H}_{2} \mathrm{SO}_{4}, 100{ }^{\circ} \mathrm{C}$, with annealing; $6-20 \% \mathrm{H}_{2} \mathrm{SO}_{4}, 100{ }^{\circ} \mathrm{C}$, with annealing; $7-10 \% \mathrm{H}_{2} \mathrm{SO}_{4}, 80{ }^{\circ} \mathrm{C}$, without annealing.

The research made by authors, in order to determine the corrosion resistance of titanium and its alloys with the deposited metallic powders, has shown that their corrosion speed can be reduced by 100 times in water solution containing $10-40 \% \mathrm{H}_{2} \mathrm{SO}_{4}$ at the temperature of $100{ }^{\circ} \mathrm{C}$, and, in the case of additional subjecting, the annealing process and 
the corrosion speed can be reduced by more than 100 times, with the intention of homogenizing the structure of the layer and developing the diffusion processes of the elements deposited in the material of the piece.

These layers allow to increase the corrosion potential up to $+400 \mathrm{mV}$ in $10 \% \mathrm{H}_{2} \mathrm{SO}_{4}$ solution at $80{ }^{\circ} \mathrm{C}$ and up to $+300 \mathrm{mV}$ at $100{ }^{\circ} \mathrm{C}$, while the titanium, in the absence of protective depositions, dissolves very actively at the potential of $-0.56 \mathrm{mV}$.

Finally, we can conclude that the deposition of anticorrosive coatings on the surfaces of titanium and its alloys pieces can be applied in the construction of machines, ensuring a considerable duration of their functionality in aggressive environments.

\section{The results of research on the corrosion properties of oxide films}

In the researches carried out by the authors, the results of the experimental measurement of active electrical surface resistance for the samples made of C45 steel, processed by applying PEDM, under atmospheric conditions, at room temperature, are presented both for the surface of the anode electrode samples and for the surface of cathode workpiece (Table 1).

\begin{tabular}{|c|c|c|c|c|c|}
\hline \multirow{2}{*}{ Sample } & \multicolumn{5}{|c|}{ Electrical surface resistance, $\times 10^{6} \Omega \cdot \mathrm{mm}^{-2}$} \\
\hline & \multicolumn{4}{|c|}{ Experimental data } & Average value \\
\hline \multirow{5}{*}{ Cathode } & 0.88 & 0.72 & 1.46 & 0.71 & \multirow{5}{*}{0.98} \\
\hline & 0.97 & 1.52 & 0.68 & 0.72 & \\
\hline & 0.73 & 1.09 & 0.76 & 0.83 & \\
\hline & 1.33 & 1.10 & 1.04 & 0.73 & \\
\hline & 1.07 & 0.88 & 1.21 & 0.78 & \\
\hline \multirow{5}{*}{ Anode } & 0.81 & 0.26 & 0.46 & 0.31 & \multirow{5}{*}{0.33} \\
\hline & 0.11 & 0.14 & 0.56 & 0.34 & \\
\hline & 0.29 & 0.11 & 0.62 & 0.38 & \\
\hline & 0.87 & 0.38 & 0.11 & 0.15 & \\
\hline & 0.12 & 0.13 & 0.27 & 0.17 & \\
\hline
\end{tabular}

Table 1

The electrical surface resistance of the unprocessed samples by PEDM plasma ranges from $0.05 \div 0.09 \Omega \cdot \mathrm{mm}^{-2}$. From the analysis of the experimental results presented in Table 1 , we can state that, in all cases, there is a substantial increase in the surface of active resistance of the electrodes (both of anode and cathode) that participated in the PEDM process, but the active surface resistance of the anode-electrode sample is about 3 times smaller than that of the cathode-workpiece sample.

The last finding can be explained by the fact that at the surface of the anode, under the same conditions, a higher amount of energy is released and possibly more intense vaporization processes take place and, on the other hand, the oxygen ions are predominantly directed by the forces of the electric field from the gap to the cathode surface, which is why the intensity of the oxide film formation is less intense on the anode surface.

Further (Table 2), the measurements of the surface electrical resistance of the superficial layer for cathode samples made from titanium, aluminium and copper alloys were made. 
Electrical surface resistance of oxide films formed on the workpiece-cathode surfaces

\begin{tabular}{l|c}
\hline Processed sample material & $\begin{array}{c}\text { Average value of surface resistance, } \times 10^{6} \\
\Omega \cdot \mathrm{mm}^{-2}\end{array}$ \\
\hline Titanium alloy BT8 (TiAl6Mo4) & 1.6 \\
\hline Duralumin Д16 (AlCu4Mg1) & 0.25 \\
\hline Technically pure copper M0 & 0.15 \\
\hline Bronze БpA5 (Cu95Al5) & 0.17 \\
\hline Brass Л63 (Cu63Zn37) & 0.19 \\
\hline
\end{tabular}

As can be seen from the results presented in Tables 1 and Table 2, the electrical surface resistance is a function of the material of the investigated samples and has higher values for the materials with increased oxygen avidity.

If we analyze the obtained results, we can see that, for the case of processed samples made of $\mathrm{C} 45$ steel, the corrosion speed in $3 \% \mathrm{NaCl}$ water solution, at the applied voltage of 2 $\mathrm{V}$, is, practically in all cases, twice lower than for the unprocessed samples by oxidation. The speed of corrosion of titanium samples with oxide films in $30 \% \mathrm{H}_{2} \mathrm{SO}_{4}$ water solution at $80{ }^{\circ} \mathrm{C}$ decreases by about 100 times comparatively with the unprocessed titanium surfaces.

If it is taken into account that the potential for natural corrosion is tens and hundreds of times less than in the case of the tests carried out, then the effectiveness of the application of oxides and hydroxides, in the amorphous state, will increase more significantly. Finally, we can admit that the application of amorphous oxides and hydroxides to metal surfaces by PEDM is beneficial for increasing their active corrosion resistance.

\section{The corrosion resistance of the graphite film}

When samples are placed in electrolyte, in the absence of external electric current, a stationary potential is established. In the case when both electrodes are made from the same type of steel, the stationary potential is almost zero and, in the case when the anode is covered with graphite, the stationary potential is $0.1 \mathrm{~V}$. It is observed that, for the steel sample, with the increasing potential, an increase in current intensity occurs as well, up to the value of $2 \mathrm{~V}$, followed by an area where a decrease of intensity occurs up to the value of 2.9 V. This effect may be due to the oxidation and hydroxylation chemical reactions that lead to the steel surface passivation, in the absence of the graphite film. After this value with increasing the potential difference the corrosion current decreases and the corrosion process takes place at low speed, i.e. passive film emerges, which does not allow anodic dissolution. The passive state is maintained until the potential of $2.8 \mathrm{~V}$, then the current intensity increases considerably, accelerating the corrosion process.

From the analysis results, related to corrosion speed variation, depending on the duration of samples exposure in aggressive environment, we can outline essentially higher corrosion rates for the initiation stage of corrosive process, in the case of unprocessed Steel 45 without a graphite pellicle. Afterwards, with the passing of time, the process of corrosion is attenuated; the determined corrosion rate is smaller, when the time of immersion is longer. Similarly, with the passing of time, the nature of the corrosion product is modified, oxides are most likely formed, having a low oxygen content and being more stable $\left(\mathrm{Fe}_{3} \mathrm{O}_{4}\right)$ $\left(\mathrm{FeO} \cdot \mathrm{Fe}_{2} \mathrm{O}_{3}\right)$.

In the case of steel coated with graphite film, lower corrosion rates are found; 
afterwards, they begin to rise due to degradation of graphite film, as a result of its destruction.

It was experimentally established that in acid solution of $30 \% \mathrm{HNO}_{3}$, after 3 minutes, the amount of uncovered graphite steel electrochemically dissolved 1.4 times greater than graphite-coated steel - 1.3 times greater in 10 minutes. In salt solution of $1 \% \mathrm{NaCl}$, the amount of uncovered graphite steel electrochemically dissolved was 1.2-1.4 times greater than graphite-coated steel deposited by PEDM.

Instead of the less pronounced increase of anti-corrosion properties comparatively with the surface with oxide and hydroxide films, the graphite films formed on the same steel C45 surface increases the superficial microhardness, the functional durability and the processing productivity of the active piece surfaces.

\section{Conclusions}

Analyzing the results of the experimental researches, we can conclude the following:

- the thermal treatment, in the absence of liquid phase formation on the processed surface, can be performed only in the regime of maintenance of the electrical discharge in impulse on "cold" electrode spots;

- under superficial processing conditions, with the maintenance of electric spell released on "cold" electrode spots, the mass transfer in the solid phase can reach depths dozens of $\mu \mathrm{m}$ diameters, which will allow the working surfaces of the parts and cutting tools of the layers with prescribed physic-mechanical properties that will provide them with high performance features;

- the thermal and chemical-thermal processes that result in the surface layers of the parts under the action of the plasma channel of the electrical discharges in impulse cause not only the modification of their chemical composition, but also the modification of their physical and mechanical properties;

- the oxide films, formed as a result of the interaction with PEDM plasma, increase the resistance by $10^{6}-10^{7}$ times, which, in turn, influences the corrosion resistance.

\section{References}

1. Nanu, A. Technology of Materials. Chisinau: Stiinta, 1992, 552 p.

2. Topala, P., Ojegov, A. Formation of oxide thin pellicles by means of electric discharges in pulse, Annals of the Oradea University. Fascicle of management and technological engineering, volume VII (XVII), 2008. CD-ROM Edition. Edition of University from Oradea, Romania. ISSN 1583-0691, CNCSIS „Class B+”, pp. 1824-1829. DOI: 10.15660/AUOFMTE.2008.1213

3. Nanostructures and Thin Films for Multifunctional Applications. NanoScience and Technology / Ed.: Tiginyanu, I., Topala, P., Ursaki, V., Springer International Publishing Switzerland, 2016. 576 p. ISSN 1434-4904, ISBN 978 3-319-30197-6. DOI 10.1007/978-3-319-30198-3.

4. Tian, B.R., Cheng, Y.F. Electrochemical corrosion behaviour of X-65 steel in the simulated oil sand slurry. I: Effects of hydrodynamic condition, Corrosion Science, Volume 50, Issue 3, March 2008, pp. 773-779.

5. YING, L.L., Wang, L.F. Electrochemical Corrosion Behaviour of Nano crystalline Materials - a Review, Journal of Materials Science \& Technology, Volume 26, Issue 1, January 2010, pp. 1-14.

6. Rihan, O.R. Electrochemical corrosion behaviour of X52 and X60 steels in carbon dioxide containing saltwater solution, Mat. Res., vol.16, no.1, São Carlos Jan., 2013.

7. Kuphasuk, Ch. et.al. Electrochemical corrosion of titanium and titanium-based alloys, The Journal of Prosthetic Dentistry, February 2001, Volume 85, Issue 2, pp. 195-202.

8. Huang, Ch.-L. et.al. Electrochemical Corrosion and Mechanical Properties of Two Biomedical Titanium Alloys, Int. J. Electrochem. Sci., 13 (2018) 2779 - 2790, two: 10.20964/2018.03.26.

9. Song, G.L. The grand challenges in electrochemical corrosion research, Front. Mater., 10 March 2014 । https://doi.org/10.3389/fmats.2014.00002. 
10. Tian, G. et.al. Investigation on electrochemical corrosion characteristic of $2 \mathrm{~A} 14$ aluminum alloy in nitric acid, Surf. Rev. Lett. 24, 1850016 (2017) [10 pages] https://doi.org/10.1142/S0218625X18500166.

11. Topala, P. Research on obtaining deposition layers from metallic powders by applying pulsed electric discharge machining. Ph.D. Thesis Review. Bucharest: University Politehnica, 1993, 32 p.

12. Topala, P.A., Balcanuta, N.P. Electro-dynamical characterization of electric discharge impulses. Modern technologies, quality, restructuring. Chisinau: Technical University of Moldova, 2001, pp. 203-208.

13. Topala, P. Conditions of thermic and thermo-chemical superficial treatment innards with the adhibition of electric discharge in impulses. Nonconventional technologies review. Bucharest: Editura BREN, 2005, p. 27-30.

14. Topala, P. Applications of electroerosion in the development of fine surface processing technologies. The Annals of the Alecu Russo Balti State University, Fasc. A, 2004, Vol. XX, pp. 66-69.

15. Topala, P.A., Gitlevichi, A.E., Kornienko, L.P. Corrosion behavior of titanium with electrospark coatings. Metal Protection, Moscow, 1989, Vol. 29, no. 3, pp. 351-356.

16. Topala, P.A. et.al. The effect of annealing on the corrosion behavior of titanium with electrospark coatings. Metal Protection, Moscow, Vol. 26, no. 3, 1990, pp. 433-437.

17. Topala, P.A. et.al. Hardening of metal surfaces in areas for electrospark alloying. Engineering and technosphere of the XXI century. Collection of papers of the XIII International Scientific and Technical Conference, Vol. 3, Donetsk, 2006, pp. 262-265.

18. Topala, P., Stoicev, P. Technologies for the processing of conductive materials by applying pulsed electric discharge machining. Chisinau: Tehnica-Info, 2008, 265 p.

19. Topala, P. Research on obtaining deposition layers from metallic powders by applying pulsed electric discharge machining. Ph.D. Thesis. Bucharest: University Politehnica, 1993, 161 p.

20. Kornienko, L.P. et.al. Electrochemical and corrosion behavior of titanium with $\mathrm{Pd}$ and $\mathrm{Cr}$-Pd electrospark coatings. Metal Protection, Moscow, 1991, Vol. 29, no. 3, pp. 351-358.

21. Chernova, G.P. et.al. The influence of annealing on the corrosive behaviour of titanium with electrospark palladium surfaces. Metal protection. Vol. 26, No. 3, 1990, pp. 433-437.

22. Parkanskiy, N.Ya. Investigations on the process of electrospark coating of powder materials in the electric field. Ph.D. Thesis Review. Kiev: Institute for Problems of Materials Science, Ukrainian Academy of Sciences, 1979, $27 \mathrm{p}$.

23. Livurdov, V.I. et.al. Structure and operational properties of parts with coatings obtained by electrospark alloying with powder materials. EMP, 1980, no. 5, pp. 33-35.

24. Parkanskiy, N.Ya., Gitlevichi, A.E. Peculiarities of the surface of the cathode layers in the electrospark deposition of powder materials. EMP, 1981, pp. 32- 35.

25. Gitlevichi, A.E. et.al. Electrospark alloying of metal surfaces. Chisinau: Stiinta, 1985, 196 p.

26. Nemoshkalenko, V.V. Features of the formation of surface layers with spark discharges. Physics of metals, Kiev, Vol. 12, no 3, pp. 132-133, 1990. ISSN 0204-3580.

27. Mitskevichi, M.K. et.al. Electroerosion processing of metals. Minsk: Nauka i tehnica, 1988, 216 p.

28. Lyubimov, G.A., Rahovskiy, V.I. Vacuum arc cathode spot. Advances in the Physical Sciences, no. 125, issue 4, 1978, pp. 665-706.

29. Bushik, A.I. Investigation of the dynamics of processes in a pulse discharge at complex electrodes. Ph.D. Thesis Review. Minsk: Institute of Physics and Technology of Academy of Sciences of Belarus, 1973, 23 p.

30. Antonov, S.A. et.al. Arc erosion of cathodes containing inclusions of emission-active phase. J. Th. Phis., no. 52, issue 52, 1982, pp. 266-270.

31. Bulat, V.E., Esterliv, M.H. Purification of metal products from dross, oxide film and pollution by electric arc discharge in vacuum. Phis. Chem. Met. Proc., 1987, no. 3, pp. 49-53.

32. Abdulkareem, M.A., Hani, A.A. The effect of $\mathrm{Zn}, \mathrm{TiN}$, and lead coating on corrosion protective effectiveness of steel reinforcement in concrete. American Journal of Scientific and Industrial Research, 2011, 2(1), pp. 89-98. ISSN: 2153-649X. doi:10.5251/ajsir.2011.2.89.98.

33. Negm, N.A. et.al. Corrosion inhibition properties of some novel $n$-methyl diethanolammonium bromide cationic surfactants. TESCE, Vol. 30, no. 2, 2004, pp. 853-869.

34. Gogoi, P.K., Barhai, B. Corrosion inhibition of carbon steel in open recirculating cooling water system of petroleum refinery by a multi-component blend containing zinc (II) diethyldithiocarbamate. Indian Journal of Chemical Technology, Vol. 17, July 2010, pp. 291-295. 